\title{
A reescrita textual e os processos de ensino e aprendizagem de alunos dos Anos Iniciais do Ensino Fundamental ${ }^{1}$
}

Textual rewriting and the teaching and learning processes of students from the Early Years of Elementary School

Resumo: Este trabalho é parte de um estudo desenvolvido no Programa de Residência Pedagógica articulado ao curso de Pedagogia do Centro Universitário Norte do Espírito Santo (CEUNES/UFES) durante os meses de agosto de 2018 a janeiro de 2020. Apresenta reflexões sobre como a atividade de reescrita pode auxiliar e contribuir significativamente no processo de escrita e elaboração textual. A pesquisa foi realizada em uma Escola Municipal de São Mateus - ES, situada em uma comunidade com alta vulnerabilidade social infantil. Neste texto, buscou-se analisar a produção textual de uma das crianças, matriculada no $4^{\circ}$ ano do ensino fundamental, a partir do desenvolvimento de um projeto de intervenção que nasceu através de um diagnóstico realizado pela Secretaria Municipal de Educação em que foram detectadas as inúmeras dificuldades de escrita dos alunos. A metodologia utilizada foi a pesquisa qualitativa com observação, participação e coleta de dados através do diário de campo com anotações das práticas educativas instauradas na sala de aula. Os resultados da pesquisa, a partir da produção textual dos alunos, mostram o quanto a utilização da reescrita é importante para a construção do sujeito-autor e produtor de textos.

Palavras-chave: Ensino Fundamental. Produção de Texto. Reescrita. Leitura e Escrita. Alfabetização.

Abstract: This work is part of a study developed in the Pedagogical Residency Program articulated to the Pedagogy course of the North University Center of Espírito Santo (CEUNES/UFES) during the months of August 2018 to January 2020. It presents reflections on how the rewriting activity can help and contribute significantly in the process of writing and textual elaboration. The research was conducted in a Municipal School of São Mateus - ES, located in a community with high social vulnerability of children. In this text, we tried to analyze the textual production of one of the children, enrolled in the 4th grade of elementary school, from the development of an intervention project that was born through a diagnosis made by the Municipal Department of Education in which the countless difficulties of writing of the students were detected. The methodology used was qualitative research with observation, participation and data collection through the field diary with notes of educational practices established in the classroom. The results of the research, from the textual production of the students, show how important the use of the rewriting is for the construction of the subject-author and producer of texts.

Keywords: Elementary School. Text Production. Rewriting. Reading and Writing. Literacy.

1 O texto ora apresentado é parte do estudo realizado no Trabalho de Conclusão de Curso do Curso de Pedagogia do Centro Universitário Norte do Espírito Santo CEUNES/UFES 


\section{Introdução}

Esse estudo faz parte das vivências experimentadas em uma escola dos Anos Iniciais do Ensino Fundamental, na atuação vivida pela primeira autora do texto, como aluna residente do curso de Pedagogia. Participando das relações vividas na escola, foi possível identificar a dificuldade dos alunos em escrever e produzir textos. Em virtude desse aspecto, foram elaboradas algumas propostas de intervenção como parte do Programa de Residência Pedagógica ${ }^{2}$ e, nesse estudo, iremos analisar um dos projetos de intervenção desenvolvidos na área da leitura, escrita e produção de texto.

A ideia do projeto surgiu a partir de uma leitura de textos de diagnóstico elaborada para atender uma demanda da Secretaria Municipal de Educação de São Mateus-ES. Nesse diagnóstico, percebemos que os alunos não tinham domínio na aprendizagem de como estruturar um texto. Todos os textos estavam escritos de forma corrida, sem acentuação, pontuação, sem utilizar parágrafos e com pouca coerência de sentidos. A partir disso, a ideia de trabalhar com a reescrita se fortaleceu. Mas porque reescrita? Reescrever textos de qualidade é importante para que o aluno entre em contato com a leitura e a escrita de modo que possa aprender a escrever levando em conta a forma como se escreve, o que se escreve, para quem se escreve e em que condições de produção se escreve.

Sabemos que a escrita possui um papel relevante na sociedade em que vivemos. Ela perpassa diferentes contextos e desempenha inúmeras funções na vida das pessoas logo, o seu domínio, é uma exigência que é indispensável para a participação social. Embora a produção textual seja um tema bastante discutido em pesquisas acadêmicas, haja quantidade razoável de literatura de referência nessa área e dos documentos oficiais para o ensino da produção textual, o domínio da escrita está distante "de garantir a todos os seus alunos o acesso aos saberes linguísticos, necessários para o exercício da cidadania, direito inalienável de todos" (BRASIL, 1997, p.15). Por isso, apresentamos aqui

\footnotetext{
2 Segundo o edital Capes n 06/2018 - Retificado, a Residência Pedagógica é uma atividade de formação realizada por um discente regularmente matriculado em curso de licenciatura e desenvolvida numa escola pública de educação básica, denominada escola-campo.
} 
algumas reflexões sobre as concepções de linguagem, leitura e escrita para trazer a reescrita como uma ferramenta principal de melhora das escritas e leitura do aluno (ANTUNES, 2003).

A reescrita é considerada como um dos fatores essenciais do processo de produção textual, uma vez que é escrevendo seu texto e o reescrevendo que o aluno aprenderá e conseguirá apropriar-se do sistema de escrita, desenvolvendo-se como o sujeito principal do texto. Com base na reflexão sobre o papel de extrema importância que a escrita exerce na sociedade, este estudo tem como foco trazer uma reflexão sobre a produção de textos escritos e reescritos a partir de seus usos sociais e busca responder à seguinte questão de pesquisa: em que medida a reescrita pode contribuir para 0 aprimoramento da produção escrita pelos alunos?

Para responder a essa problematização, esse estudo tem como objetivos compreender como a reescrita textual contribui para os processos de aprendizagem da leitura e da escrita de alunos dos anos iniciais do ensino fundamental, analisando o processo de aprendizagem nos vários momentos das reescritas textuais e desenvolver um projeto de intervenção pedagógica que trabalhe com diferentes versões de um mesmo texto.

Inicialmente, buscamos realizar a pesquisa bibliográfica com base em autores que analisam o processo de escrita e leitura de forma mais específica, evidenciando dessa maneira a reescrita como uma ferramenta relevante para a aprendizagem do aluno (ANTUNES, 2003; GASPAROTO E MENEGASSI, 2013). Desse modo, a pesquisa bibliográfica ajudou a fazer o planejamento das atividades desenvolvidas durante o projeto.

\section{A importância da reescrita na formação do aluno-autor}

A prática de escrita consiste em um processo que depende de várias etapas para que possa ser realizada com sucesso. Concordamos com Antunes (2003, p. 54) quando "ressalta que a escrita compreende etapas distintas e integradas de realização (planejamento, operação e revisão), as quais, por sua vez, implicam da parte de quem escreve uma série de decisões". 
Logo, cada etapa do processo pressupõe como ficará a estrutura final do texto. A primeira etapa seria preparar o aluno ao receber o texto. Escolher 0 gênero, planejar, ensinar as características e fazer a leitura do gênero escolhido para que o aluno estabeleça uma relação significativa com texto. Antunes (2003, p. 55) nos diz que,

$\mathrm{Na}$ escolha dos critérios de ordenação das ideias, é relevante prever como a informação vai ser distribuída ao longo do texto, isto é, por onde se vai começar, que sequência se vai adotar, como se vão dividir os tópicos em subtópicos e em que ordem eles vão aparecer.

A segunda etapa seria a produção do texto na qual o professor propõe ao aluno uma ideia de produção interessante deixando claro que o texto vai circular dentro do ambiente escolar e que sua escrita tem como objetivo final manifestar suas opiniões e reflexões para um leitor, ou seja, ele escreve para alguém. Assim, quando o aluno se propõe a produzir um texto, o professor deverá destacar a importância da coerência e da coesão, responsáveis, respectivamente, pelo sentido do texto e pela conexão entre as partes. Sob o mesmo ponto de vista, Antunes (2003, p. 55) argumenta que,

A segunda etapa, a etapa da escrita, corresponde à tarefa de pôr no papel, de registrar o que foi planejado. É a etapa da escrita propriamente dita, do registro, quando concretamente quem escreve toma as decisões de ordem lexical (a escolha das palavras) e de ordem sitático-semântica (a escolha das estruturas das frases), em conformidade com o que foi anteriormente planejado e [...] com as situações concretas de comunicação. Sempre atento, sempre em estado de reflexão, para garantir sentido, coerência, relevância.

A terceira etapa envolve a correção que o professor acompanhado do aluno fará ao texto. Segundo Gasparoto e Menegassi (2013) o processo de revisão abre caminho para a etapa seguinte da reescrita. $O$ processo de revisão e reescrita não são práticas muito comuns na escola, pois, nota-se que a preocupação geral dos alunos é entregar o texto para o professor, como um produto acabado, de modo a garantir notas para o bimestre. Desse modo, a etapa de revisão e reescrita perde seu significado. Cabe ao professor se inteirar de que essa etapa poderá ajudar o aluno ao longo do ano letivo a 
melhorar sua escrita, e que a correção não precisa ser realizada apenas por ele, mas também pelo próprio aluno ou outro colega.

Um outro fato importante a se destacar é a estratégia que o professor utiliza para correção desses textos. Faz-se necessário que o mesmo compreenda que é preciso diferenciar o conceito entre correção e revisão. Segundo Ruiz (1998, p.19),

Correção é o trabalho que o professor, visando à reescrita do texto do aluno, faz neste mesmo texto, no sentido de chamar a sua atenção para algum problema de produção, para alguma infração textual. Correção é, pois, o texto que o professor faz por escrito no (e de modo sobreposto ao) texto do aluno, para falar desse mesmo texto.

É imprescindível que o docente tenha estratégias interventivas, orais ou escritas, para levar o aluno a perceber os problemas de seu texto e dar conta deles. $O$ ato de revisar o texto faz com que o aluno a partir dessas orientações antecedidas pelo professor, releia e encontre em seu próprio texto essas discordâncias sobre o que ele diz na sua escrita e o que gostaria de ter dito, é a ação, portanto, de rever sua produção e até reestruturá-la. Corrigir é orientar a revisão e a reescrita, de modo a observar se as principais características do gênero foram contempladas na produção do aluno, bem como, os problemas de contradição, de continuidade e de progressão.

Na quarta etapa é onde acontece o movimento da reescrita. É imprescindível que o aluno tenha o direito de reescrever e rever seus textos de forma que isso se torne um hábito para ele. Assim como afirma Antunes (2003, p. 65) "talvez seja preferível que os alunos escrevam menos, mas que possam revisar seus textos, até mais de uma vez, tornando-se essa revisão, assim um hábito já previsto nas atividades escolares da escrita".

Portanto, a reescrita permitirá o aluno ajustar sua forma de dizer dentro de determinado gênero controlando aspectos do texto que sejam formais e/ou gramaticais. Desta maneira, o aluno ao considerar as observações do professor, assumindo o papel de "[...] leitor-corretor-avaliador, utiliza-se dessas sugestões externas para reformular seu texto [...]" refletindo também na sua escrita anterior, calhando no seu amadurecimento enquanto escritor (MENEGASSI, 1998, p.6). 
Ainda nessa perspectiva, Menegolo \& Menegolo (2005, p. 77), ressaltam que,

[...] Ainda nesse processo de reescritura, o sujeito-aluno precisará se reconstruir enquanto sujeito-autor, ou seja, não se trata apenas de uma (re) construção textual, mas de uma nova afirmação de sua autoria e de seu discurso, em que ele tomará novas posições, de acordo com os discursos implícitos e explícitos no texto original, que foi alterado de alguma forma pelo professor. Conforme for (re) construindo sua enunciação, irá também se (re) constituindo enquanto sujeito-autor [...].

O aluno ao ter contato com seu próprio texto durante o momento de reescrita poderá estabelecer uma relação de confiança em relação a sua produção textual permitindo que ele tenha um olhar mais crítico e se enxergue nesse processo como um sujeito- avaliador.

Segundo Menegolo e Menegolo (2005, p. 74),

A importância do ato de reescritura de textos reside no fato de que provoca o diálogo do sujeito-autor com o seu produtocriado, possibilitando um relacionamento mais interativo com seu próprio texto (confrontamento, aguçamento e exclusão de enunciados). O aluno sai, ao reescrever, do estágio emocional (inspirativo), que gera a primeira escrita, e passa ao estágio de maior racionalização sobre o que foi materializado.

E continua,

E, neste encontro de um "eu-escritor" com um "tu-reescritor", que só pode acontecer no que Bakhtin (1997, p. 289-290) chama de "cadeia da comunicação verbal", o aluno não é um mero receptor, pois, ao receber [seu texto, [com apontamentos do professor], tende a compreender.

[...] a significação (lingüística) de um discurso e adota, simultaneamente, para com este discurso, uma atitude responsiva ativa: ele concorda ou discorda (total ou parcialmente), completa, adapta, apronta-se para executar, etc., e esta atitude do ouvinte está em elaboração constante durante todo o processo de audição e de compreensão desde o início do discurso [...].

Esse processo faz com que o aluno tenha um novo olhar para seu texto, observando detalhes que antes não percebera. Por isso, quanto mais houver o exercício da reescritura dentro da sala de aula, mais o educando notará que sua produção textual poderá ser modificada, e que seu texto "[...] não é um 
produto de dimensões significativas acabadas" (MENEGOLO \& MENEGOLO, 2005, p. 75).

Com isso, a reescrita cumpre seu papel como ferramenta auxiliar da produção textual, revelando-se para o aluno, através da mediação do professor, que o processo de escrita e reescrita é um processo criativo que demanda uma postura autônoma. O discente, então, ao realizar sua reformulação aprende sobre determinado gênero textual utilizando dos mecanismos certos para a construção desse, e se torna leitor crítico de seu próprio texto e se reconstrói criando novos sentidos e significados adequandose a norma de estrutura textual.

É importante que haja um trabalho contínuo do professor para que ao longo do percurso o educando se desenvolva nesse processo. Logo, concluímos que a reescrita é um instrumento de aprendizagem e deve, portanto, fazer parte do processo da escrita textual, uma vez que a primeira versão de um texto-enunciado, dificilmente, atenderá a todos os objetivos da produção.

\section{Metodologia da pesquisa: o caminho percorrido}

Esta pesquisa foi desenvolvida por meio da participação no Programa de Residência Pedagógica, com o subprojeto relacionado ao curso de Pedagogia do Centro Universitário Norte do Espírito Santo. As atividades da Residência Pedagógica foram iniciadas em agosto do ano de 2018 e se findaram em janeiro de 2020, numa escola situada na cidade de São Mateus/ES cuja comunidade era socioeconomicamente desprivilegiada e com grande vulnerabilidade social infantil. As observações e anotações sobre o dia a dia na sala de aula foram recursos essenciais para o desenvolvimento desta.

A turma analisada foi a do $4^{\circ}$ ano do ensino fundamental, considerada a turma com mais dificuldades de aprendizagem da escola. No início do ano de 2019, foi realizado um diagnóstico pela Secretaria Municipal de Educação que evidenciou os problemas de escrita apresentados pelos alunos, em sua maioria repetentes. A partir desse momento a ideia de criar um projeto de intervenção 
que contribuísse com o processo de aprendizagem desses alunos se fortaleceu e muitas ideias surgiram.

As observações e as anotações em caderno de campo serviram para dar o primeiro passo. Refletindo sobre as questões do estudo, percebemos que na sala de aula os alunos não tinham o hábito da leitura, muito menos eram incentivados para isso. Notamos também a dificuldade de criarem uma simples história. Foi decidido, então, ler todos os dias os mais variados livros de literatura, buscando estimular nas crianças o desejo e a curiosidade pela leitura, de modo que pudessem desenvolver sua criatividade $\mathrm{e}$ consequentemente a sua imaginação. É sabido que a possibilidade de criar/imaginar está ligada ao contexto histórico, familiar, escolar e à riqueza de experiências vivenciadas pela criança. E, como atividade humana, esta é semioticamente mediada pela cultura.

Segundo Vigotski (2009, p.42),

[...] Nenhuma invenção ou descoberta científica pode emergir antes que aconteçam as condições materiais e psicológicas necessárias para seu surgimento. A criação é um processo de herança histórica em que cada forma que sucede é determinada pelas anteriores.

Considerar o meio familiar em que os alunos viviam, as formas de como estes interagiam e utilizavam a linguagem dentro da sala de aula foi um ponto muito importante para saber quais metodologias de ensino usar com as crianças.

Perceber os alunos enquanto sujeitos culturais, possibilitou refletir de acordo com o que Gomes e Monteiro (2005, p. 24) retratam,

É fundamental levar em conta o contexto sócio-cultural de nossos alunos ao se ensinar a ler e a escrever. Do ponto de vista da psicologia sócio-histórica, mostra-se essencial saber quem são as crianças, seus interesses, seu cotidiano, seus gostos culturais, suas práticas de leitura e de escrita. $\mathrm{O}$ que eles já sabem sobre leitura e escrita também são fatores fundamentais a serem considerados nesse processo. Vivemos num mundo da escrita e nossos alunos já chegam com alguns conhecimentos sobre a língua que vivenciam em seu cotidiano. Esses conhecimentos precisam ser valorizados e considerados ao se ensinar a ler e a escrever, tendo em vista os grupos sócio-culturais aos quais os alunos pertencem. 
Mediante isso, percebemos a necessidade de promover, a princípio, experiências voltadas para leitura e escrita que fossem significativas o suficiente para que o processo de aprendizagem fosse construído através das nossas interações durante as aulas. $O$ ato de ler para eles todos os dias antes do início das aulas efetivamente, começou a alimentar a imaginação dos alunos. Eles tinham mais criatividade para realizar os desenhos e também de pegar livros na biblioteca para ler para os colegas da turma. Esse processo de estímulo e experiência leitora fez com que a sala de aula se tornasse um ambiente de construção de uma imaginação criadora.

Além dessa mediação, durante o ano de 2019, foi desenvolvido dois projetos com os alunos do $4^{\circ}$ ano: o primeiro com o título "O uso da reescrita como ferramenta auxiliar da produção de texto utilizando as várias versões do conto: Chapeuzinho Vermelho". Foi trabalhado o gênero conto com os alunos, explicando suas características e a estrutura do texto. Os alunos tiveram contato com as várias versões da Chapeuzinho Vermelho por meio de livros e filmes e também atividades interdisciplinares das disciplinas de história, artes e educação física.

Fizemos um texto coletivo da história e desenhos para representá-la. Esse primeiro projeto trouxe bastante motivação aos alunos no sentido de possibilitar novos tipos de vivências, trabalhar o dinamismo da aprendizagem fora da sala de aula foi um dos pontos fortes desse primeiro projeto.

O segundo projeto intitulado: "O Uso da reescrita como ferramenta auxiliar da produção de texto utilizando o gênero textual: conto" foi realizado no período de agosto de 2019 a novembro de 2019, como continuação do desenvolvimento e da aprendizagem que os alunos tiveram com a intervenção passada. E foi a partir dessa proposta que inserimos os alunos no mundo da escrita e da reescrita como forma de mediar o processo de aprendizagem. As atividades foram baseadas no gênero textual 'conto'. Escolhemos permanecer neste gênero por perceber que durante as leituras que eram feitas, os alunos se interessavam mais por contos. 
De acordo com Musialak e Robaszkievicz (2013, apud SOARES, 1993) conto é a designação de uma narrativa curta e se diferencia do romance e da novela por características estruturais e pelo tamanho.

Segundo Fiorussi (2003, p. 103),

Um conto é uma narrativa curta. Não faz rodeios: vai direto ao assunto. No conto tudo importa: cada palavra é uma pista. Em uma descrição, informações valiosas; cada adjetivo é insubstituível; cada vírgula, cada ponto, cada espaço - tudo está cheio de significado. [...]

Além de ser uma narrativa curta, o conto possui uma estrutura própria com elementos textuais que são essenciais em um conto escrito, tais como o enredo, o conflito, os personagens, o lugar e principalmente o tempo. Como esse trabalho de reconhecimento das características de um conto já tinha sido feito no projeto anterior, o ponto de partida seria focar nas produções de escrita e reescrita dos alunos.

De acordo com Silva e Tullio (2016, p.10),

O trabalho com os gêneros textuais da esfera da criação literária levando ao letramento é um grande desafio, pois deve atender às necessidades do educando haja vista o papel da escola que é formar leitores e escritores críticos, ou seja, aqueles que perpassam os limites do texto. Se os educandos não forem capacitados serão cada vez mais massa de manobra, isto é, a pensar conforme o sistema quer.

Dessa maneira, ressaltamos a importância da continuidade do trabalho com gêneros textuais e da formação continuada para que o professor se reinvente com novas estratégias para o ensino de diferentes possibilidades de escrita de textos na escola. Nesse contexto, na pesquisa que ora é apresentada, destacamos os detalhes e as especificidades do segundo projeto desenvolvido com os alunos no período de agosto de 2019 a dezembro de 2019 no Programa "Residência Pedagógica”.

\section{Análise das experiências com a reescrita}

As questões indicadas acima serão agora retomadas para análise da experiência com a reescrita na escola onde a pesquisa foi realizada. Os dados obtidos neste estudo são importantes indícios do percurso de escrita e reescrita 
do qual os alunos, participantes desta pesquisa, foram se constituindo e se modificando na complexa relação entre eles, sujeitos singulares e a linguagem.

Nesta seção, procedemos à análise dos dados relacionados à questão central da pesquisa, qual seja, em que medida a reescrita pode contribuir para o aprimoramento da produção escrita pelos alunos? $E$ o desdobramento para atender ao objetivo desse estudo que é analisar o percurso da escrita e da reescrita dos contos produzidos por uma aluna do $4^{\circ}$ ano de uma escola municipal auxiliados por um protocolo de procedimento de reescrita.

Valendo-nos da concepção interacionista como orientação para a análise dos dados coletados, mostraremos o percurso da escrita e reescrita e, assim, evidenciaremos que a cada reescrita o aluno vai se apropriando da estrutura/esquema temática do gênero conto, ampliando por sua vez o domínio da língua escrita, e consequentemente, resignificando seu texto.

Nos limites desse texto, apresentaremos o processo de escrita e reescrita da aluna Beatriz $^{3}$, desenvolvido durante a aplicação do projeto intitulado: O Uso da reescrita como ferramenta auxiliar da produção de texto utilizando o gênero textual: conto".

Durante as atividades de reescrita, Beatriz demonstrou interesse no processo e ficou empolgada ao saber sobre a confecção de um livro. Nas atividades desenvolvidas pela pesquisadora ${ }^{4}$, a aluna desmonstrava uma facilidade de produzir o texto quando sentava em dupla ou em grupo com alguns de seus colegas. Essa experiência comprova a importância do valor e do papel das interações na sala de aula quando se trabalha com leitura e escrita. Assim como confirma Gomes e Monteiro (2005, p. 28): "[...] o que conta como aprendizagem da leitura e da escrita no contexto da sala de aula só pode ser analisado se são consideradas as interações discursivas, as ações dos participantes [...]".

A pesquisadora trabalhou bastante a dinâmica de produção textual em pequenos grupos dentro da sala de aula. Porém, ao ser observada anteriormente, podemos perceber que a aluna apresentava dificuldades em sua

\footnotetext{
${ }^{3}$ Nome Fictício.

${ }^{4}$ Aluna do curso de Pedagogia e participante/bolsista do Programa de Residência Pedagógica.
} 
produção textual quando tinha que escrever sozinha. A professora regente não tinha o hábito de trabalhar com os textos, e quando fazia, o trabalho era apenas a leitura do mesmo e atividades de interpretação de texto presentes nos livros didádicos.

Entendemos que esse tipo de prática deve ser realizada de forma muito cuidadosa, pois sua rotina poderá tornar o ensino engessado. Diante disso, o hábito da professora fazia com que a aluna e outros se sentissem desmotivados e desinteressados para a leitura ativa no ambiente da sala de aula. Segundo Guimarães (2001, p. 37),

Um indivíduo intrinsecamente motivado procura novidade,
entretenimento, satisfação da curiosidade, oportunidade para
exercitar novas habilidades e obter domínio. Está implícita
nesta condição uma orientação pessoal para dominar tarefas
desafiadoras, associada ao prazer derivado do próprio
processo.

Quando o aluno está inserido em um espaço onde ele recebe estímulos de leitura e escrita criativa, o próprio aluno desenvolverá o desejo de participar das atividades dentro da sala de aula. Conforme descrito na metodologia, o gênero textual trabalhado para a escrita e reescrita textual foi o conto "A Bela Adormecida", conto este, bastante conhecido por todos os alunos. 


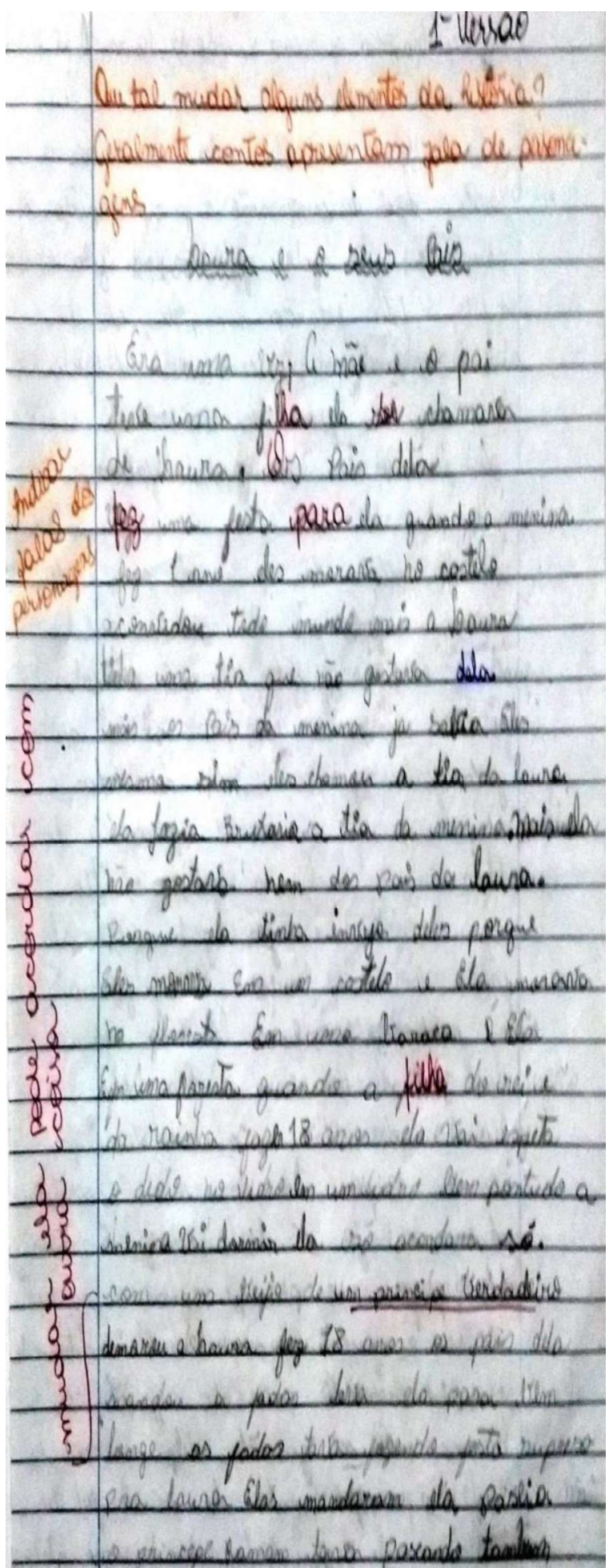

Fonte: Arquivo pessoal da pesquisadora (2019)

Observa-se que a aluna ao escrever sua primeira versão materializou suas ideias de modo significativo, de acordo com as características do gênero. 
No início, ela apresentou os personagens e o lugar onde morava. No meio do conto, a aluna desenvolveu a trama, trazendo um clímax no seu enredo. E trouxe como desfecho um final feliz resolvendo assim a vida dos personagens. De uma forma geral, a aluna já de antemão, com todo o processo ao qual ela foi apresentada (contextualização do gênero), conseguiu desenvolver sentidos com relação às ideias escritas no texto.

Em relação à ortografia e estruturação do texto, a aluna se mostrou mais atenta ao reler sua produção, na qual a mesma foi apontando os erros. A pesquisadora ao mediar esse processo, deu algumas sugestões para que a aluna alterasse algumas características de sua produção. Como a proposta era recriar uma nova versão, foi enfatizado para a turma utilizar a imaginação e trazer novos elementos à versão particular, mantendo algumas características da história. A professora pesquisadora utilizou de perguntas para induzir as respostas na aluna/autora do texto produzido.

A aluna se encontrava na fase alfabética, que na perspectiva psicogenética, como afirma Ferreiro e Teberosky (1986, p. 213, apud SOARES, 2018, p. 236) é a fase final da evolução da escrita, "[...] a partir desse momento a criança se confrontará com as dificuldades própria de ortografia, mas não terá problemas de escrita, no sentido estrito". Poderá, sim, apresentar problemas no sentido amplo do processo de escrita, pois a mesma precisa aprender a escrever de acordo com as normas de ortografia do sistema alfabético. Como aconteceu em alguns momentos do texto onde a aluna escreve algumas hipóteses de palavras como "filia", "cansão", "siquiam", "soutaram".

No primeiro momento, o foco de intervenção não foi nas palavras escritas de modo incorreto e sim ensinar a aluna a evidenciar em seu texto, os significados das escritas produzidas para se fazer entender a um interlocutor. Dito isso, é importante que o processo de construção seja valorizado e que os erros sejam analisados como hipóteses constitutivas do processo de ensinoaprendizagem, pois "a relativização do erro amplia as possibilidades de aprender e de ensinar, como também as possibilidades de intervenção do 
professor como agente provocador e reequilibrador" (GOMES E MONTEIRO, 2005, p. 36).
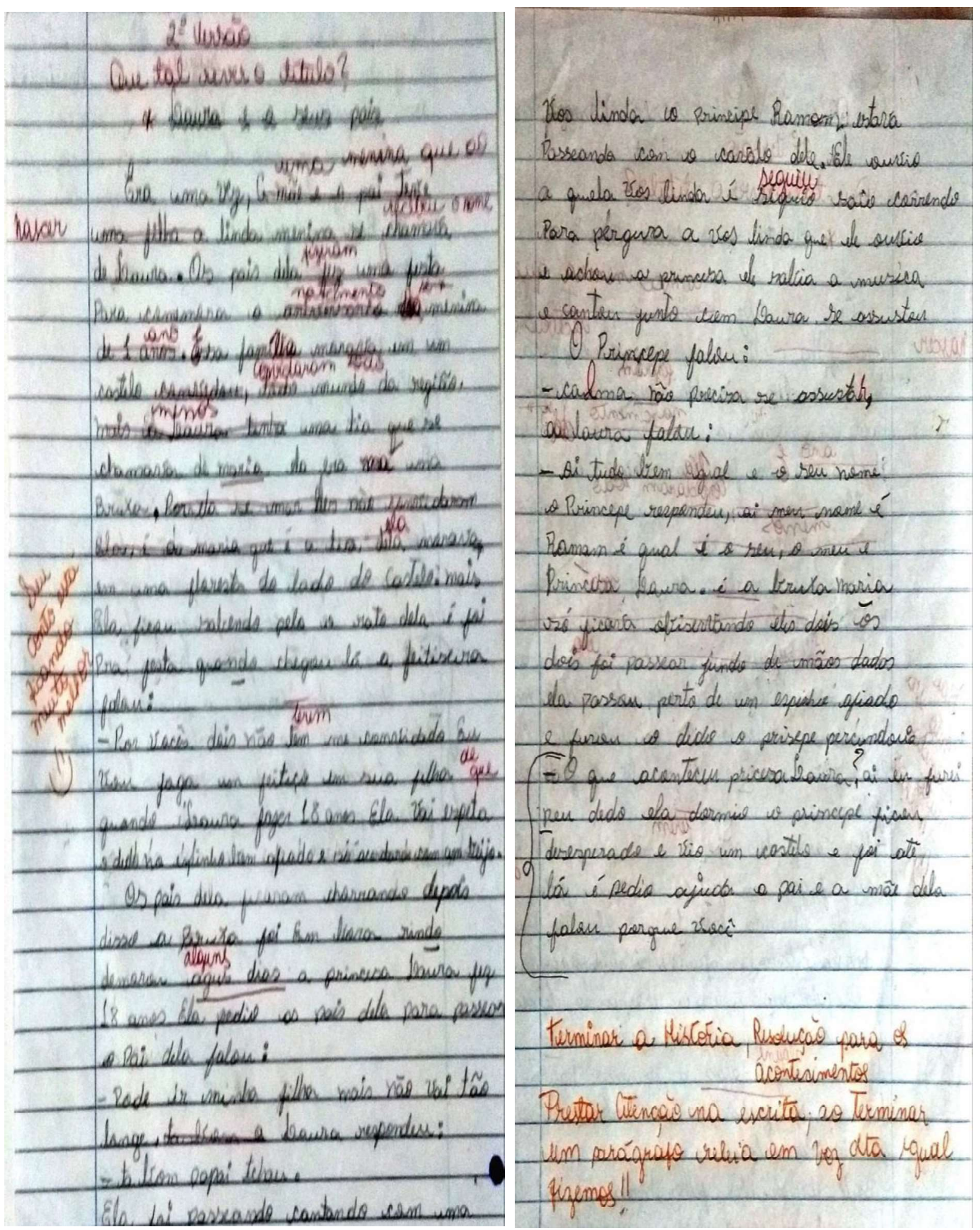

Figura 2 - $2^{a}$ versão do conto

Fonte: Arquivo pessoal da pesquisadora (2019) 
Na segunda versão do conto, podemos notar que a aluna já escreve o texto se apropriando das pontuações necessárias, embora tenha se esquecido de utilizá-las em sua primeira versão, a mesma ao fazer a leitura de seu próprio texto, foi adequando suas ideias às novas produções textuais elaboradas.

A professora pesquisadora sugeriu uma mudança de título, frases para melhorar o sentido do texto, descrever melhor a vilã da história, nomear, criar falas durante o enredo da trama, sugerir a criação de uma nova maldição diferente da história original etc. Essa mediação foi feita juntamente com aluna, de forma individual, para que não se perdesse a subjetividade e autoria que estava presente ali.

Figura 3 - Versão final do conto
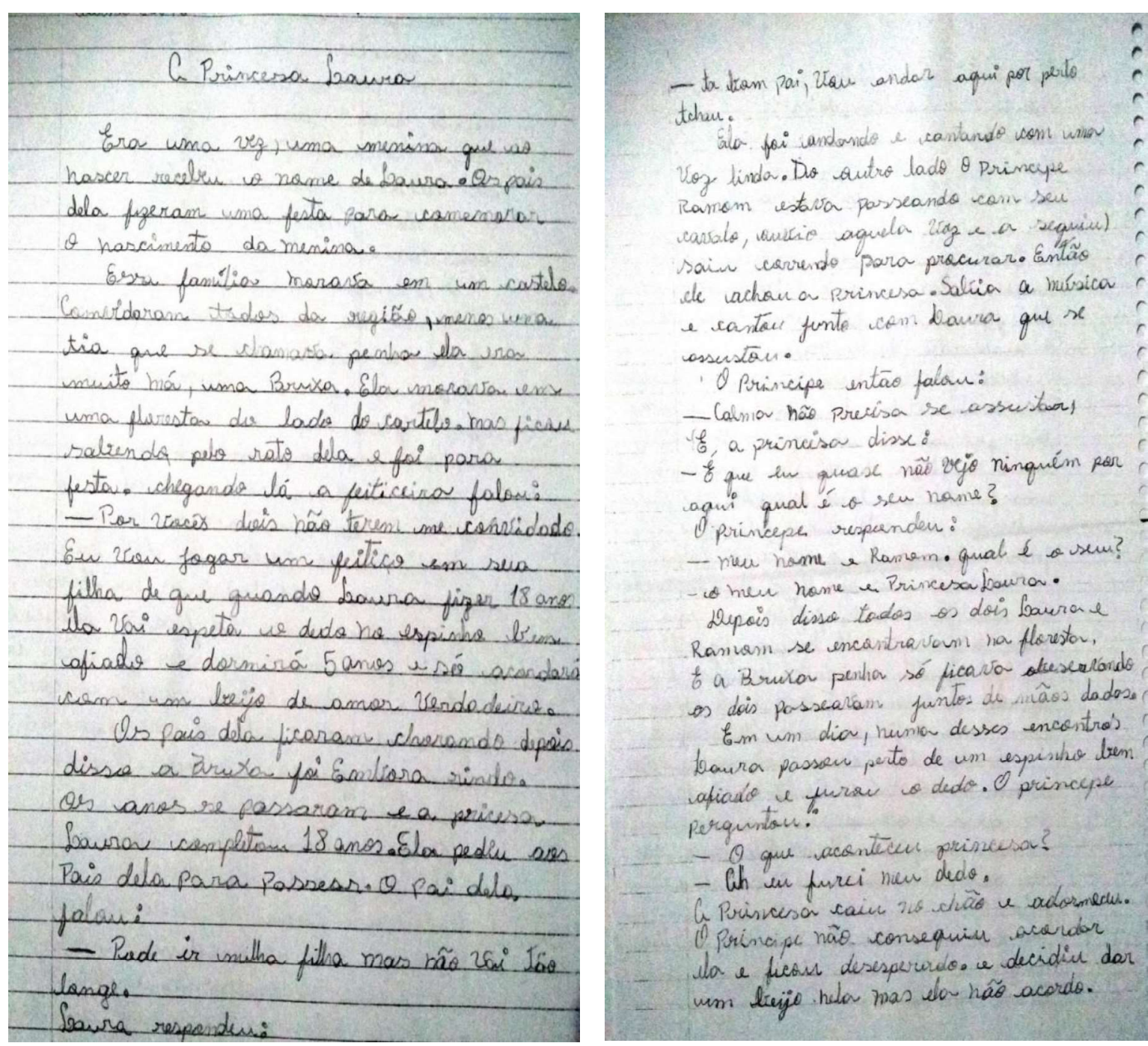

Fonte: Arquivo pessoal da pesquisadora (2019) 
$\mathrm{Na}$ versão final do conto, a produção de sentido do texto ficou muito melhor que a primeira. A aluna atingiu a habilidade de escrita de conseguir transmitir sua mensagem em seu texto de forma subjetiva, de acordo com seu nível de desenvolvimento.

Seu texto passou a ter mais parágrafos, buscou diferenciar suas falas enquanto narradora, demarcou a fala dos seus personagens através do ponto "travessão" e corrigiu sua escrita no momento de produção de seu texto. Nesse sentido, salientamos que a reescrita é um processo contínuo que a criança deverá aprender a realizar na medida em que seus anos escolares forem passando.

\section{Considerações Finais}

Para finalizar este estudo, apresentamos as considerações finais a respeito dos sentidos produzidos nas produções textuais dos alunos do $4^{\circ}$ ano do ensino fundamental. Uma turma que ao início do projeto tinha muita dificuldade para desenvolver escritas e não tinha interesse pela leitura. Como já foi explicitado, a pesquisa foi resultado de vivências experimentadas no Programa de Residência Pedagógica do CEUNES/UFES, do curso de Pedagogia com o período de duração de 18 meses.

Após as reflexões e análises das produções textuais realizadas nesse estudo, foi possível notar a importância e necessidade da leitura e escrita serem trabalhadas em sala de aula, sem negligenciar $\mathrm{o}$ aspecto da compreensão do texto, mas que propicie uma construção de textos ricos, escritos pelas próprias crianças. Isso vai de acordo com o que Antunes (2003, p. 67) nos diz sobre "a atividade da leitura complementa a atividade da produção escrita. É, por isso, uma atividade de interação entre sujeitos e supõe muito mais que a simples decodificação dos sinais gráficos [...]". Pode-se evidenciar que foi de fundamental importância a prática do professor mediador, que orienta, que conduz e estimula o aluno de forma dialogada.

As atividades prévias de leitura e escrita, foram essenciais pois serviram como ponto de partida do processo de desenvolvimento e aprendizagem dos alunos. Segundo Gomes (2005, p. 37) "a aprendizagem e desenvolvimento são 
concebidos como processos interdependentes e contínuos, cuja natureza pressupõe que um seja convertido no outro". Dessa maneira, podemos inferir que a aprendizagem das crianças não se dá apenas no seu nível individual, mas também coletivo, mediante a interação com os colegas.

Partindo desse pressuposto, trazer a produção textual evidenciando as práticas de revisão e reescrita foi um grande desafio que só foi possível pela sequência de atividades introdutórias realizadas anteriormente. A ação de escrever e reescrever o conto várias vezes causou estranhamento nos alunos, por ir além do que eles já estavam habituados a fazer nesse tipo de atividade de produção escrita. Mas, apesar do estranhamento dos alunos no início da escrita e após a confecção do livro, percebemos uma extrema satisfação e orgulho quando viram seus contos sendo lidos pelos professores e alunos de outras turmas. Isso revela que o objetivo de fazer com que eles compreendessem a importância da reescrita para o aprimoramento do seu texto, foi atingido. Apesar da proposta não ter atingido todos os alunos e não ter superado todas as dificuldades de escrita, a melhora foi significativa, sendo assim, colocamos em evidência a continuidade de práticas de revisar e reescrever textos.

Embora as atividades e ações empreendidas ao longo desta pesquisa fossem em certa medida padronizadas, cada aluno desenvolveu seu percurso de escrita e reescrita tendo as suas individualidades respeitadas e valorizadas. Como pesquisadora e residente do curso de Pedagogia foi possível sempre me colocar como interlocutora do aluno, ao longo do percurso empreendido na sua produção escrita e durante o processo da reescrita.

Destacamos aqui a necessidade de mais estudos na universidade voltados para a prática do professor na sala de aula no trabalho com o texto e produção textual escrita concebida pela concepção de linguagem enquanto interação.

\section{Agradecimentos}

À CAPES, pelo apoio financeiro ao Programa de Residência Pedagógica e pelas bolsas concedidas. 


\section{Referências}

ANTUNES, Irandé. Aula de português: encontro e interação. São Paulo: Parábola Editorial, 2003.

BRASIL. Parâmetros Curriculares Nacionais: Língua Portuguesa. Brasília: MEC/SEF, 1997.

FIORUSSI, André. De conto em conto. In: Antônio de Alcântara Machado et alii. São Paulo: Ática, 2003.

GOMES, Maria de Fátima Cardoso; MONTEIRO Sara Mourão. A Aprendizagem e o Ensino da Linguagem Escrita. Caderno do Professor. Belo Horizonte: Ceale/FaE/UFMG, 2005. 84 p. - (Coleção Alfabetização e Letramento)

GASPAROTO, Denise Moreira; MENEGASSI, Renilson José. A mediação do professor na revisão e reescrita de textos de aluno de Ensino Médio. Calidoscópio. Vol. 11, n. 1, p. 29-43, jan/abr 2013.

GUIMARÃES, Sueli Édi Rufini. Motivação intrínseca, extrínseca e o uso de recompensas em sala de aula. In: BORUCHOVITCH, Evely; BZUNECK, José Aloyseo. A motivação do aluno: Contribuições da Psicologia Contemporânea. 2 ed. Petrópolis, RJ: Vozes, 2001.

MENEGASSI, Renilson José. Da revisão à reescrita: operações e níveis lingüísticos na construção do texto. Assis, SP. Tese de Doutorado. Faculdade de Ciências e Letras de Assis. Universidade Estadual Paulista, 1998, 228 p.

MENEGOLO, Elizabeth Dias Wallace; MENEGOLO, Leandro Wallace. O significado da reescrita de textos na escola: a (re) construção do sujeito autor. Ciências \& Cognição. v. 5, p. 73 - 79. Março/2005. Disponível em: www.cienciasecognição.com.org. Acesso em 13/11/2019.

RUIZ, Eliana M.D. Como se corrige redação na escola. Tese (doutorado) Universidade Estadual de Campinas, Instituto de Estudos da Linguagem. Campinas, 1998.

SILVA, Nilceia de Paula da; TULLIO, Cláudia Maris. Gênero Textual Conto Uma Forma de Comunicação e Expressão. DESAFIOS DA ESCOLA PÚBLICA PARANAENSE NA PERSPECTIVA DO PROFESSOR. Artigos/ volume I. Versão Online. Cadernos PDE. 2016.

SOARES, Magda. Alfabetização: A questão dos métodos. São Paulo: Contexto, 2018.

SOARES, Magda. Linguagem e Escola: Uma perspectiva social. 10.ed. São Paulo: Ática, 1993.

SOLÉ, Isabel. Estratégias de Leitura. 6.ed. Porto Alegre: Artmed, 1998. 
VIGOTSKI, Lev. Semionovich. Imaginação e criação na infância: ensaio psicológico. Apresentação e comentários de Ana Luiza Smolka. Tradução de Zoia Prestes. São Paulo: Ática, 2009.

\section{Sobre os autores}

Isabel Karoline Pinheiro Santos

isabelkarolinesantos@hotmail.com

Graduada em Pedagogia pelo Centro Universitário Norte do Espírito Santo. Universidade Federal do Espírito Santo (CEUNES/UFES).

\section{Rita de Cassia Cristofoleti}

ritadecassiacristofoleti@gmail.com

Doutora em Educação pela Universidade Estadual de Campinas (UNICAMP, 2015). Professora do Departamento de Educação e Ciências Humanas da Universidade Federal do Espírito Santo, Centro Universitário Norte do Espírito Santo UFES/CEUNES. Professora do Programa de Pós-Graduação em Ensino na Educação Básica do Centro Universitário Norte do Espírito Santo (UFES/CEUNES).

Docente orientadora do Programa de Residência Pedagógica do curso de Pedagogia do Centro Universitário Norte do Espírito Santo (CEUNES/UFES), edital Capes n06/2018 - Retificado. 